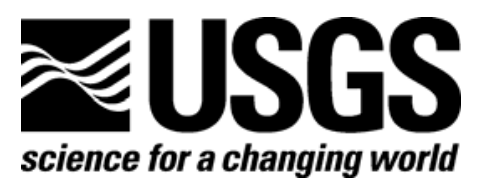

\title{
Use of NEXRAD to Study Shorebird Migration in the Prairie Pothole Region: A Feasibility Study
}

By Cynthia P. Melcher, Susan K. Skagen, and Lori Randall

Open-File Report 2006-1033

U.S. Department of the Interior

U.S. Geological Survey 


\section{U.S. Department of the Interior \\ Gale A. Norton, Secretary}

\section{U.S. Geological Survey \\ P. Patrick Leahy, Acting Director}

\section{U.S. Geological Survey, Reston, Virginia 2006}

For product and ordering information:

World Wide Web: http://www.usgs.gov/pubprod

Telephone: 1-888-ASK-USGS

For more information on the USGS - the Federal source for science about the Earth, its natural and living resources, natural hazards, and the environment:

World Wide Web: http://www.usgs.gov

Telephone: 1-888-ASK-USGS

Suggested citation: Melcher, C.P., Skagen, S.K., Randall, L., 2006, Use of NEXRAD to study shorebird migration in the prairie pothole region: A feasibility study: U.S. Geological Survey, Biological Resources Discipline, Open-File Report 2006-1033, 8 p.

Any use of trade, product, or firm names is for descriptive purposes only and does not imply endorsement by the U.S. Government.

Although this report is in the public domain, permission must be secured from the individual copyright owners to reproduce any copyrighted material contained within this report. 


\section{Contents}

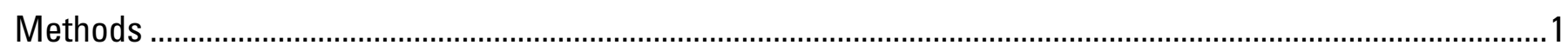

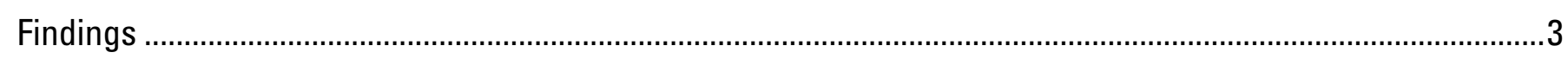

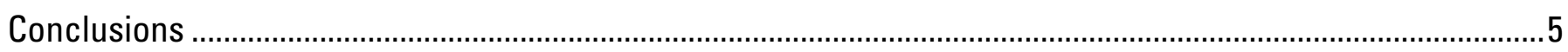

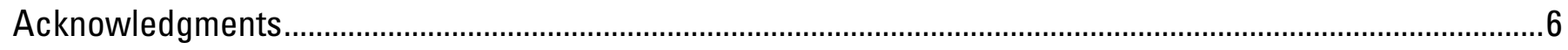

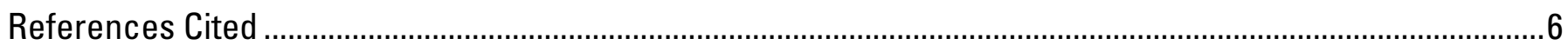




\title{
Use of NEXRAD to Study Shorebird Migration in the Prairie Pothole Region: A Feasibility Study
}

\author{
By Cynthia P. Melcher, Susan K. Skagen, and Lori Randall
}

An essential component of shorebird conservation is identifying, protecting, and managing high-priority stopover sites and migration habitats crucial to the long-term persistence of migrating shorebirds. Because of the tremendous variability in migrant shorebird occurrence patterns in the Prairie Pothole Region of the U.S. (Skagen 1997), it is labor- and cost-intensive to locate the majority of sites used heavily by shorebirds in any one migration period. Because WSR-88D (Weather Surveillance Radar - 1988 Doppler) or NEXRAD (NEXt generation weather RADar) has been useful for locating migrating birds and revealing migration patterns and important roosting sites of some species (e.g., Diehl and others 2003, Gauthreaux and Belser 2003), we undertook a pilot field study to determine wheTHEit also might be feasible to use NEXRAD for locating important stopover sites used by migrating shorebirds in the prairie potholes landscape. Coordinated efforts to advance the applicability of radar technology to bird conservation are underway (Ruth and others 2005).

\section{Methods}

We selected the Doppler station in Aberdeen, South Dakota (Fig. 1), on which to center the pilot study because (1) topographical or other interference in that area is minimal, (2) it is within the Prairie Pothole region where large numbers of shorebirds stop over in migration, and (3) no-cost housing was provided for the field observer at Sand Lake National Wildlife Refuge, which lies within reach of Aberdeen's Doppler radar beam (i.e., within $70 \mathrm{~km}$ of the station). Three maps were developed for the project. The first was a small-scale general locator map depicting all major roads, cities/towns, Universal Transverse Mercator (UTM) gridlines, and federal lands, along with two circles representing 20-km and 70-km distances from the Doppler station. (Twenty $\mathrm{km}$ is the distance within which there is generally too much ground clutter to safely use Doppler for biological purposes, and $70 \mathrm{~km}$ is the distance beyond which the Doppler beam may be too high to detect birds near their stopover habitat). The second map was a smallscale general locator map depicting all items listed above plus National Wetlands Inventory (NWI) wetlands (color-coded by type). The third map featured large-scale sections of the latter map for navigation and site identification in the field. 


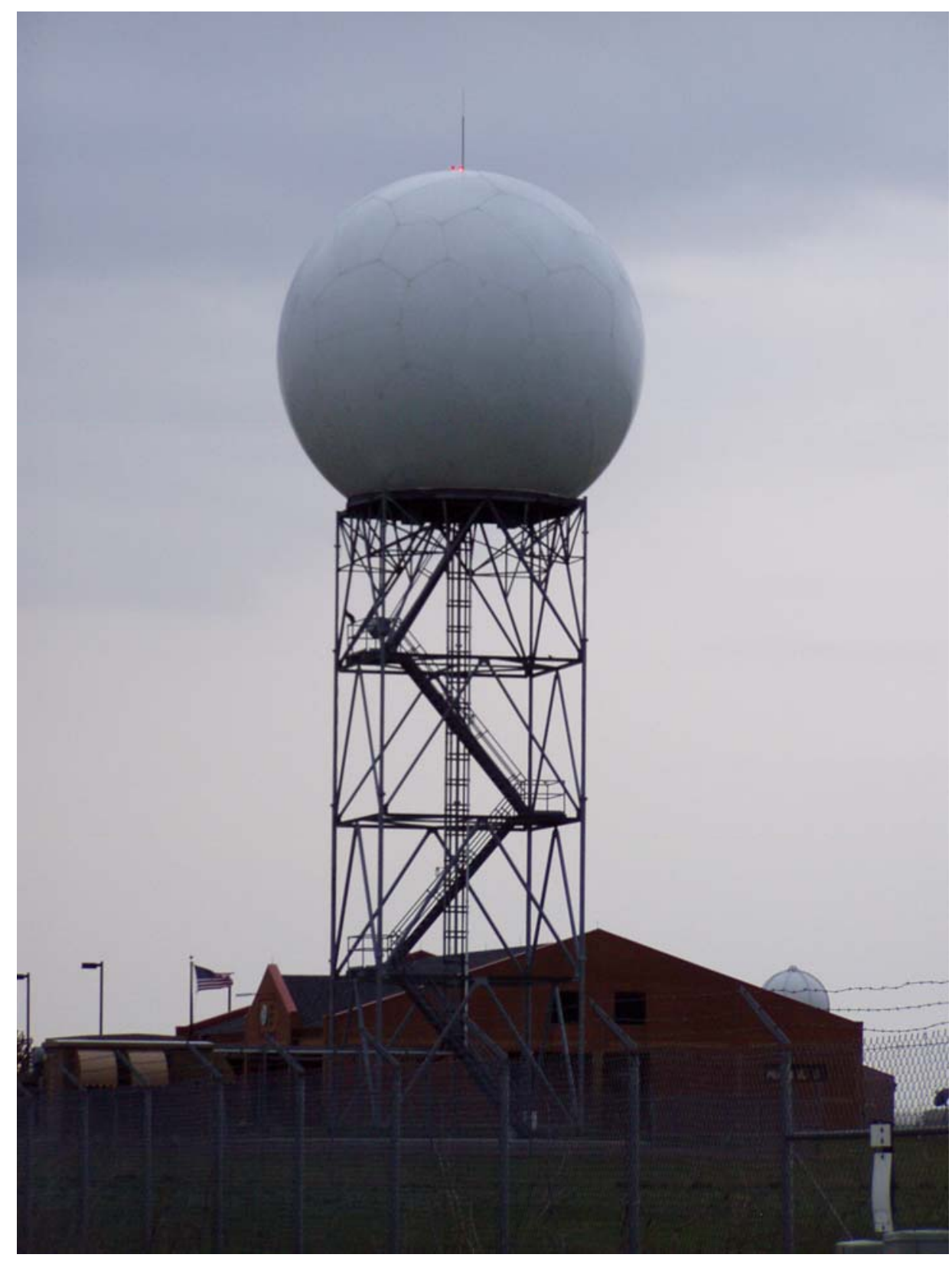

Fig. 1. Doppler NEXRAD station in Aberdeen, South Dakota.

The study was conducted via close and constant communication between remote personnel monitoring and interpreting NEXRAD images with an on-the-ground observer in the Aberdeen Doppler range. We determined which areas to avoid for bird sampling due to anomalous propagation (e.g., false echoes resulting from superrefraction of the beam, such as at the proximal edges of the Prairie and Missouri coteaus). A crucial criterion for detecting birds in NEXRAD images is that they fly high enough to be detected by the NEXRAD beam. The 
beam's floor (and ceiling) height increases with distance from the Doppler station; thus, birds must be flying higher as the observer's distance from the Doppler station increases. Height, however, is relative to elevation, both at the Doppler station and at the observer's location. For example, if the observer detects a bird where the elevation is $200 \mathrm{~m}$ higher than it is at the Doppler station, and if the beam floor is $300 \mathrm{~m}$ at the observer's location, then a bird would need to be flying at $\geq 100 \mathrm{~m}$ above the ground before radar could detect it. The beam's floor height (relative to the Doppler station's elevation) ranges from $43.5 \mathrm{~m}$ to $308.3 \mathrm{~m}$ at 20 and $70 \mathrm{~km}$, respectively, from the Doppler station. We did not concern ourselves with the beam's ceiling height (392.6 $\mathrm{m}$ to $1529.9 \mathrm{~m}$ at 20 and $70 \mathrm{~km}$, respectively, from the station), as shorebirds flying that high were not likely visible to the observer.

Our initial approach was for the observer to locate flocks (or individuals) of birds flying within the NEXRAD beam, determine the species, height, origin/direction of flight, number of birds in the flock, the observer's location, wind speed/direction, date and time of observation, and any other potentially pertinent data (e.g., other factors that could affect NEXRAD images, such as smoke from a fire, airplanes, etc.). The observer used a Davis Turbo Meter Electronic Wind Speed Indicator to measure wind speed at the ground and a Laser Atlanta Optics rangefinder to measure distance from the observer to the flock (angle between observer and bird was also measured for subsequent calculations of flock heights). A handheld compass was used to determine flight directions. Observations were recorded on audio tape and then later entered into a spreadsheet.

We compared the observer's data to NEXRAD images captured simultaneously (i.e., same time and date) at the observer's location to examine the radar images for useful information. While traveling throughout the Aberdeen Doppler range, the observer also reported sites currently in use by foraging or resting shorebirds (as well as sites used by flocks of other wetland species, such as ducks, waders, gulls, and swallows); later, NEXRAD images were scanned for evidence of shorebirds flying to and from those sites. In addition, NEXRAD staff directed the observer to locations where NEXRAD images indicated possible shorebird activity.

\section{Findings}

Field work took place from 16-25 May 2005. It was immediately apparent that most shorebirds making their daily flights between foraging sites and roosting sites do not fly high enough to be detected by the NEXRAD beam. Rather, most shorebirds flew remarkably close to the ground, often barely skimming over the habitat surface. Birds were high enough to be in the NEXRAD beam only when flocks gained flight elevation for apparent long-distance migration movements; observations of those occurrences were rare.

The American Golden-Plover (Pluvialis dominica) provided an exception. The observer discovered large flocks of these birds roosting and/or feeding in fallow (or planted but not yet sprouted) fields (Figs. 2a, 2b), and often discovered these flocks making local flights at fairly high elevations (depending on location relative to the Doppler station, sometimes high enough to be detected by the beam). The observer checked the plover roosting sites throughout the 10-day observation period, and on several occasions, witnessed large migration lift-offs as well as daily foraging flights. However, it was determined later that none of their flights were large enough to creatEa distinct pattern at the $1 \times 1 \mathrm{~km}$ spatial scale of the radar image (i.e., whether one bird or a flock of 1000 is in flight, the radar imagery still displays reflectivity at a $1^{\circ} \mathrm{x} 1 \mathrm{~km}$ spatial scale.) Accompanying this report is an animated Microsoft Power Point ${ }^{\circledR}$ presentation that captures one 

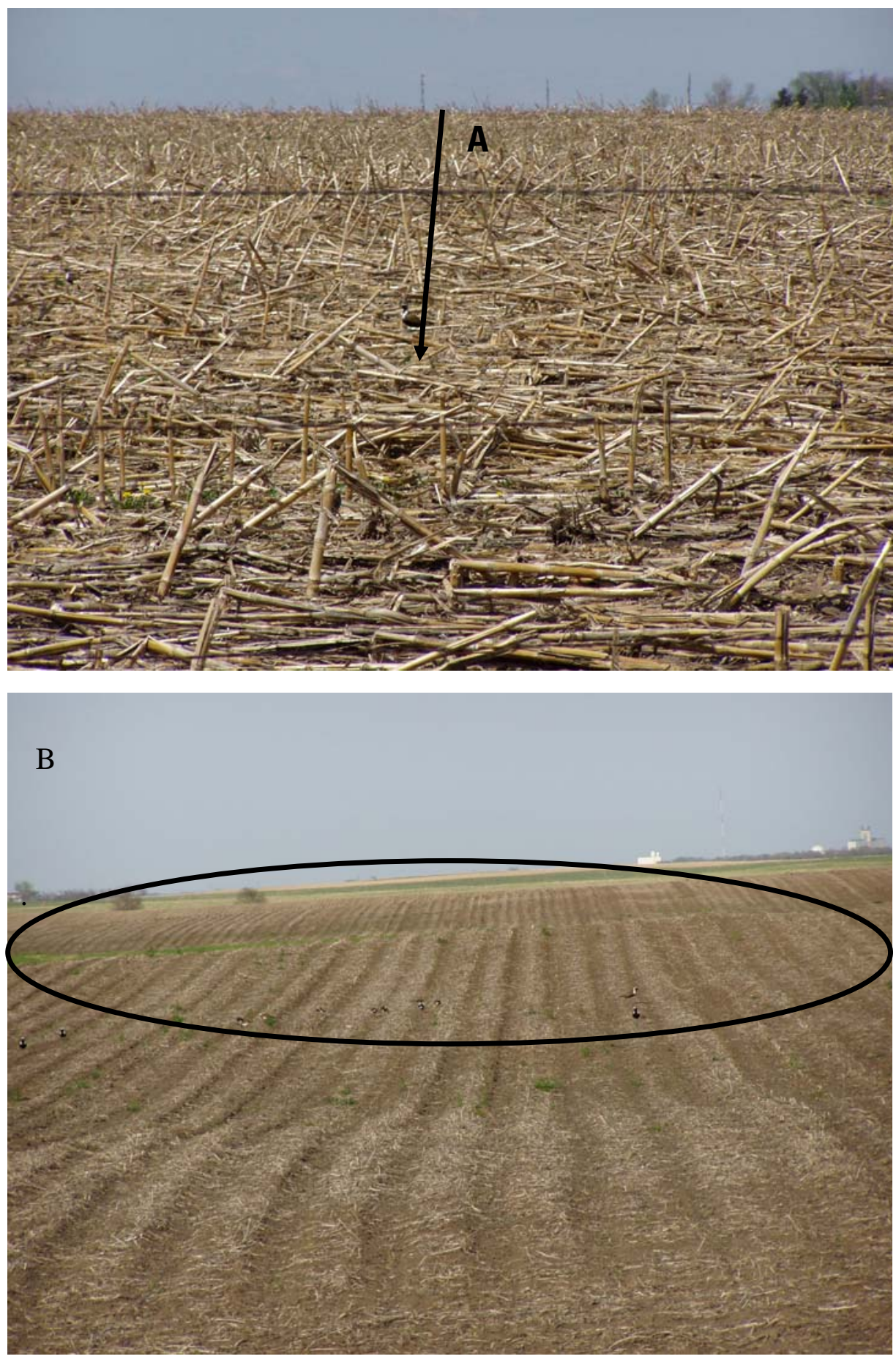

Fig. 2. Two types of fallow fields used as stopover roosting and foraging sites by American Golden-Plovers west of Aberdeen, South Dakota, 25 May 2005. The arrow in Fig. 2A points to one of $\sim 50$ plovers using a fallow corn field, and the circled area includes a group of plovers using a fallow wheat field. Overall, approximately 600-800 plovers were using fallow fields in the immediate area. 
of the larger liftoffs of American Golden Plovers on 25 May 2005. Appendix 1 describes the content of the images.

The observer recorded flights of other species (e.g., American white pelicans [Pelecanus erythrorhynchos], Franklin's gulls [Larus pipixcan], horned larks [Eremophila alpestris]) that were high enough to be detected by radar. A data file containing information on nearly 600 flights of $>40$ bird species, including GPS coordinates and estimated height, exists and is available upon request. In future work, some of these observations may be useful to compare with archived radar data to form reference data for identifying these species in flight using NEXRAD.

Clusters of apparent avian activity often aligned with landscape features. In our study area, large reflectivity values indicating significant bird activity were detected regularly north and east of the Aberdeen Doppler station. Upon investigation, it was determined that the area in question had an unusually high density of shelterbelts (relative to the overall region's shelterbelt density) and riparian woodlands; thus, it is quite likely that the high reflectivity values in that area were due to passerine migration activity.

NEXRAD staff also identified radar images that indicated flights of many birds using certain wetlands or wetland complexes, and, on several occasions, these findings led the observer to large numbers of shorebirds foraging and/or roosting at those wetlands. There was no way of knowing whether the radar images that led the observer to those sites were of shorebirds, ducks, or other waterbirds (or even swallows); however, by inspecting other wetlands of similar type and size within the same relative area, the observer often located even more shorebirds. In general, ducks, gulls, and swallows flew much higher than shorebirds as they made daily foraging flights, and may have accounted for much of the avian activity detected by NEXRAD during the study. It is likely that these species were depicted in the images that led the observer to sites hosting many shorebirds.

\section{Conclusions}

Techniques for interpreting Doppler radar data are not yet able to address the original purposes outlined in this study (i.e., distinguishing shorebirds from other "biologicals" on NEXRAD images, and using these images to locate important stopover sites in the Prairie Pothole landscape). Our recommendations for future investigations regarding applications of NEXRAD information are presented below.

To continue efforts to develop specific shorebird "signatures" from radar images, one needs to select Doppler stations that cover sites used by large numbers of shorebirds at times when few other species are likely to occur there, or when other species would be flightless (e.g., early southbound migration of shorebirds coincides in many regions with periods when waterfowl are flightless due to wing molt). Candidate sites include American Reservoir near Idaho Falls, Idaho; Bear River Migratory Bird Refuge near Salt Lake City, Utah; and Lake McConaughy in west-central Nebraska. By acquiring NEXRAD images of shorebirds that are not "contaminated" by flights of other bird species, one could possibly examine flight velocities as a means of distinguishing shorebirds (or individual species of shorebirds) from other groups of birds. Radar ornithologists and entomologists have been able to differentiate flights of birds from insects on the basis of velocities. Once shorebird "signatures" are developed, the information theoretically could be used to detect shorebirds in NEXRAD images elsewhere.

It may be feasible to use radar data to develop landscape- and climate-based models to identify areas of importance to waterbirds in general. By overlaying existing landscape data with liftoffs from radar images, we may be able to correlate bird use with landscape structure (elevation change, wetland 
cover and density, wetland types, grass cover, etc.) in dry and wet years. This could allow us to distinguish year-to-year shifts in bird distribution between wetland landscapes and give insight into the temporal dynamics of water conditions and habitat suitability for shorebirds.

\section{Acknowledgments}

The Prairie Pothole Joint Venture and the U.S. Geological Survey provided the funding to conduct this feasibility study. We thank William Schultz and the Sand Lake National Wildlife Refuge for housing and logistical support. Diane Schneider prepared the locator and NWI maps for the field work and image interpretation. Robb Diehl and Wylie Barrow provided consultation and guidance; they also provided interpretation of images as NEXRAD staff.

\section{References Cited}

Diehl, R.H., Larkin, R.P., and Black, J.E., 2003, Radar observations of bird migration over the Great Lakes: Auk, Vol.120, p. 278-290.

Gauthreaux, S. A., Jr., and Belser, C. G., 2003, Radar ornithology and biological conservation: Auk, Vol. 120, p. 266-277.

Ruth, J.M., Barrow, W.C., Sojda, R.S., Dawson, D.K., Diehl, R.H., Manville, A., Green, M.T., Kreuper D.J., and Johnston, S.,2005, Advancing migratory bird conservation and management by using radar: an interagency collaboration: Open-File Report 2005-1173, Fort Collins, Colorado: U.S. Geological Survey, Fort Collins Science Center, 12 p.

Skagen, S.K., 1997, Stopover ecology of transitory populations: the example of migrating shorebirds. Ecological Studies, Vol. 125, p. 244-269. 


\section{Appendix}

\section{Animated NEXRAD Image for a liftoff of American Golden Plovers, 25 May 2005, near Mina, South Dakota, USA.}

The following link is to a Microsoft PowerPoint ${ }^{\circledR}$ file (Appendix Mina_AGPL.ppt) contains animated versions of the two slides of NEXRAD imagery.

http://www.fort.usgs.gov/products/publications/21596/Appendix_Mina_AGPL.ppt

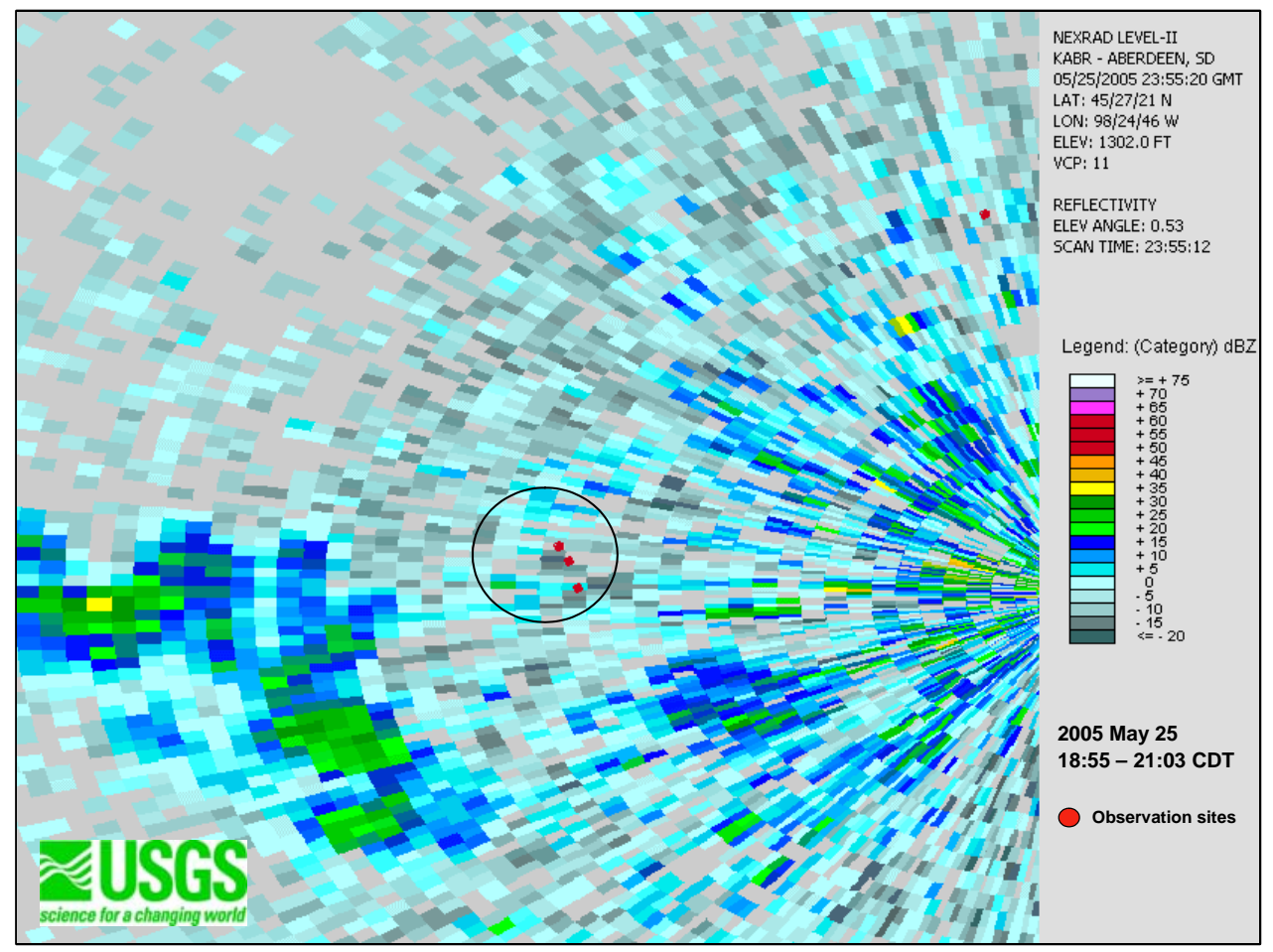

Slide 1: This image depicts the exodus of American Golden Plovers from stopover habitat as captured by the Aberdeen, South Dakota radar on 25 May 2005. Ground-based observations indicated that most of the bird activity occurred between 19:05 and 19:30 CDT (00:05-00:30 GMT). The animation runs from 18:55-21:03 CDT (23:55-2:03 GMT) in 5-6 minute increments. Rain is moving through the image from the northwest toward the southeast. Dark blue and green hues near the Mina observation sites represent the greatest numbers of birds. 


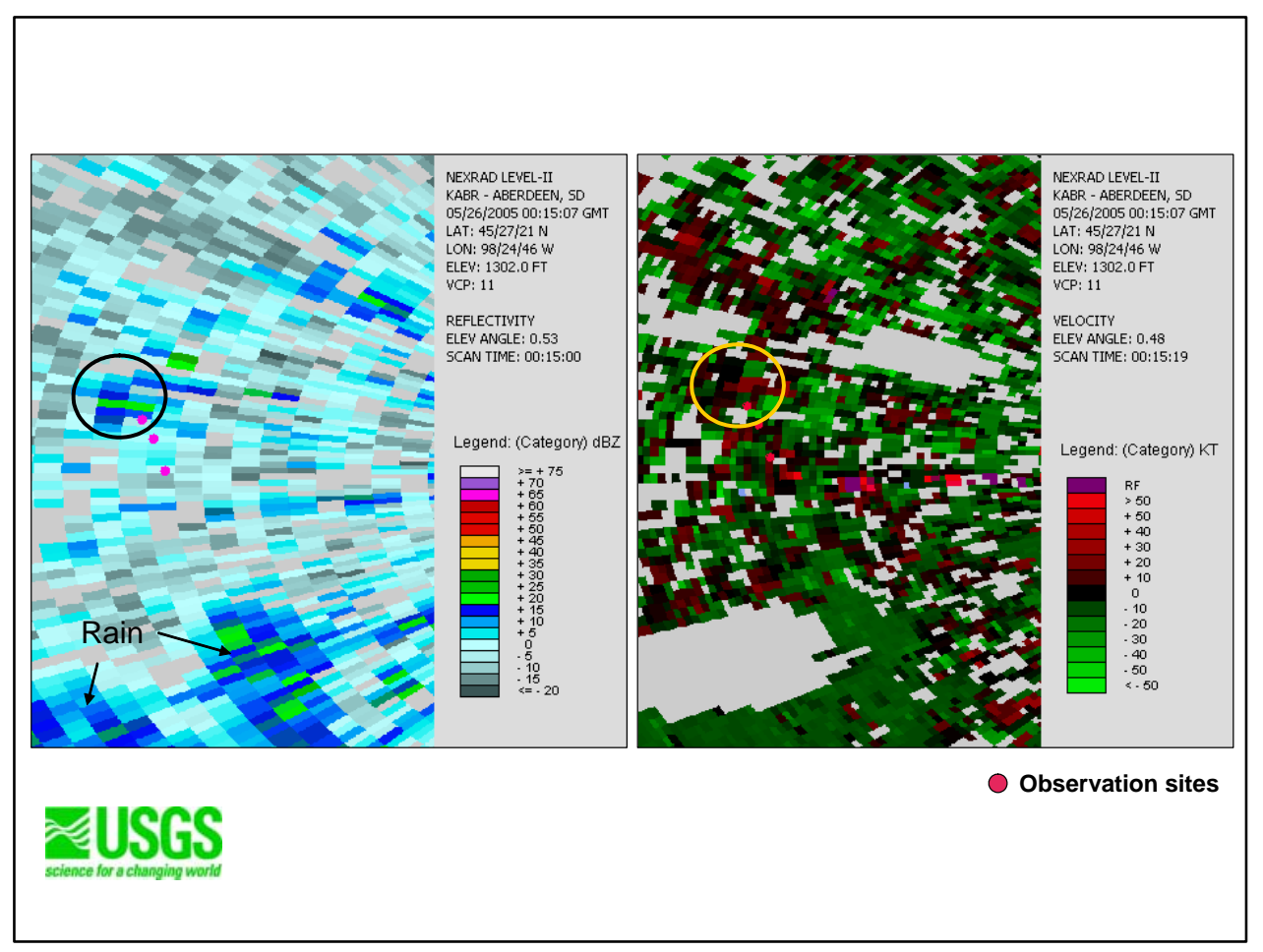

Slide 2: Reflectivity data (left) generated by American Golden Plovers departing from stopover habitat near the Aberdeen, South Dakota radar on 25 May 2005 at 19:15 CDT. Dark blue and green hues represent the greatest numbers of birds. Rain appears at the bottom of the image. The radial velocity data (right) shows the speed and direction of movement. Green hues indicate movement toward the radar and red hues indicate movement away from the radar. The echoes near the observation sites are indicative of biological activity because (1) the rain in this area appeared in multiple elevational sweeps while the reflectivity near the sites is only in the lowest elevational sweep, (2) the radial velocity data show that rain is moving towards the southeast, while targets near the sites are moving north, and (3) the spectrum width for the targets near the Mina observation sites is in the 0-6 range. 